\title{
La empresa y la administración pública: trámites y gestiones.
}

\section{Roberto Sanromán Aranda ${ }^{1}$}

\section{Resumen.}

La empresa en su desarrollo tiene muchos derechos y obligaciones, por lo que se ve en la necesidad de realizar distintos trámites y gestiones frente a la administración pública, los cuales están contenidos en las distintas leyes y reglamentos. Hay que considerar que existe un cáncer llamado corrupción, que retrasa dichas gestiones, o los vicia, por lo que tanto los servidores públicos dependientes de distintos entes de la administración pública, como las personas o gestores que tienen que realizar los trámites, deben estar limpios de corrupción y actuar conforme a principios éticos que contengan valores sólidos tendientes al bienestar, tanto de las empresas como de la administración pública en consecución del bien común de la sociedad, a quien va dirigida de los distintos grupos de consumidores finales.

Palabras clave: Empresa, administración pública, trámites, ética, corrupción.

\section{Introducción.}

A lo largo del presente artículo se abordará el tema de la empresa y la administración pública, que se encuentran inmersos en los distintos trámites y gestiones que están obligados a realizar de conformidad con los distintos reglamentos y leyes, con el fin de cumplir su objeto social en el desarrollo de sus actividades, por lo que es importante cuestionarse ¿Qué tanta importancia tienen los principios éticos en las personas que llevan a cabo los trámites o gestiones y también frente a los servidores públicos que los realizan? En la medida de que existan valores al llevar a cabo las gestiones necesarias frente a la administración pública; que los servidores públicos sean seleccionados con un servicio profesional de carrera y se combata la corrupción, que es vista como un cáncer social, no solo con paliativos sino se tomen decisiones que impacten en los servidores públicos y en la colectividad, ya que la corrupción en los trámites y gestiones de los procedimientos repercuten indirectamente y se atenta en el proceso de la producción, así como se pierde la confianza para el logro del bienestar de la colectividad y de los distintos grupos de consumidores finales a quienes van dirigido dichos servicios y productos ofertados.

\footnotetext{
${ }^{1}$ Profesor Investigador de la Universidad Autónoma del Estado de México, Centro Universitario UAEM Valle de México. Miembro del Sistema Nacional de Investigadores Nivel I. Instituición: Universidad Autónoma del Estado de México. México. E-mail: r_sanroman31@hotmail.com
} 
Como se puede inferir, el proceso productivo tiene muchos pasos y caminos, por ello lo mejor es realizarlos de manera transparente, eficaz, eficiente y en busca del mayor beneficio para la colectividad y el grupo de consumidores a quienes va dirigida.

De lo anterior se reafirma, que los trámites y las gestiones representan un gran impacto en dichos procesos productivos, mismos que no se deben escatimar ni demeritar o corromper al momento de requerirlos, en la medida que sean respetados y cumplidos cabalmente, se tendrán resultados positivos tanto para la empresa, la administración gubernamental y el público consumidor final.

\section{- De la empresa, la administración pública y la corrupción.}

La empresa está conceptualizada, conforme a la Ley Federal del Trabajo: Como la unidad económica de producción y distribución de bienes y servicios, la empresa es la actividad que desarrollan distintas personas físicas o morales, con el propósito de producir bienes u ofrecer servicios a los distintos grupos de consumidores que van dirigidos.

Para el Código Fiscal de la Federación en su artículo 16, es considerada empresa, la persona física o moral que realice actividades, a que se refiere este artículo, ya sea directamente, a través de fideicomiso o por conducto de terceros; por establecimiento se entenderá cualquier lugar de negocios, en que se desarrollen parcial o totalmente, las citadas actividades empresariales.

La empresa es un medio efectivo a través del cual se crean y transforman los productos y servicios para satisfacer las diversas necesidades de los consumidores, interviniendo en este proceso, la persona física o la persona moral como ente jurídico, reconocido por el derecho para actuar con terceros de buena fe, a través de sus representantes y éstos dentro de sus funciones tienen la posibilidad de realizar distintas actividades que requieren las empresas para su desarrollo societario, dentro de los que destacamos, los trámites y gestiones que sean requeridos por las leyes o los reglamentos, acuerdos y circulares administrativas respectivas en la administración pública.

A mayor detalle, la empresa es dirigida por el empresario, que es: " El jefe de la empresa, el que guía, coordina y dirige las actividades de los demás dentro de la empresa, a menudo el que asume los riesgos, el capitalista.

El más noble producto de la actividad empresarial es la innovación productiva... ve lo que sus competidores no ven: un nuevo producto, un nuevo método de fabricación, una nueva oportunidad de progreso económico, de satisfacción de los consumidores. "(Aguilar, 2007: 146-147) Como se desprende de lo anterior, el empresario es un líder que debe llevar 
a la empresa a los mejores resultados, buscando innovaciones o creaciones con su respectiva originalidad, que compitan en el mercado de los consumidores. Por lo que todo este proceso debe estar llevado a cabo de manera ética y responsable y para lograrlo, como una parte del proceso, implica realizar distintos trámites y gestiones frente a las autoridades, tales como licencias o permisos, por mencionar algunos.

Es complejo definir la empresa, sin embargo se ha considerado como: "El conjunto de personas y cosas organizadas por el titular con el fin de realizar una actividad onerosa, generalmente lucrativa de producción o de intercambio de bines o de servicios destinados al mercado. "(Ibíd: 149)

Por otra parte, la administración pública está formada por todos aquellos elementos o instituciones u organismos que están dentro del gobierno y que tienen por objeto administrar y optimizar los diferentes recursos y bienes para el logro de satisfactores que deben tener la sociedad dentro de sus distintos grupos colectivos. "la administración, en su aspecto dinámico, se puede explicar cómo la serie de etapas concatenadas y sucesivas dirigidas a obtener metas y objetivos predeterminados de un conjunto social, mediante el aprovechamiento racional de sus elementos disponibles.” (Fernández: 90)

A mayor abundamiento, las empresas pueden ser de distintos tipos, públicas, privadas, lucrativas, no lucrativas, sin embargo todas ellas buscan la prestación de un servicio o la producción de bienes que sean, en principio de utilidad para la colectividad o del grupo de consumidores finales.

En la medida que dichos servicios y productos sean de calidad se satisfarán las necesidades y se logrará cumplir con los fines sociales tanto de las empresas como de las instituciones que ofrecen al público dichos productos o servicios, que pueden ser ofertados tanto por entes privados como públicos.

Como parte de la administración pública, se deben tener claros sus planes de desarrollo, metas u objetivos que son establecidos en función de los requerimientos de la colectividad, por lo que dichos planes, pueden ser a corto, mediano y largo plazo dependiendo del proyecto que se dé y de las necesidades sociales, ya sean apremiantes o no lo sean. Los distintos planes y objetivos de la administración pública, deben ir conforme al plan rector, conocido como Plan Nacional de Desarrollo que se presenta cada seis años por el Presidente de la República a nivel Federal. Cabe mencionar que cada institución o dependencia pública tiene su plan de desarrollo, sus objetivos y metas que dependen se sus fines sociales o societarios. Dichos planes de desarrollo deben incluir, principios éticos lo que llevará a la 
creación de códigos de conducta, que han de estar contenidos en las distintas instituciones y que deben ser cumplidos por sus integrantes.

Así como la administración pública tiene diferentes planes, en el ámbito privado, también existen distintos objetivos que tienen las empresas sujeto su objeto social y de los bienes y servicios que ofrezca al público consumidor, serán establecidos dichos planes y objetivos, por periodos cortos, medianos o largos, dependiendo de las necesidades que se den en el desarrollo de la misma empresa. También las instituciones privadas deben contar con principios éticos y códigos de conducta.

Para el logro y cumplimiento de los planes y objetivos de las empresas, se implementan distintos trámites y gestiones dentro de la administración pública en el que hacer, para el desarrollo de la agenda pública, lo que implica el contacto constante entre el sector público y privado en busca de sus fines sociales que deben ser llevados a cabo de un modo responsable frente a las sociedad o colectividad que van dirigidos.

Debe existir contacto entre el sector público y privado, incluso la colectividad a través de los ciudadanos deben cooperar activamente con dichos sectores para el mejor logro de sus fines u objetivos, en la medida que exista transparencia en las actuaciones y se evite la corrupción, los resultados serán serios para las mismas y por consecuencia para la sociedad o la colectividad a la que se debe.

Ambas empresas como públicas y privadas deben contar con empleados que se encarguen de sus actividades con el propósito de lograr sus fines; como el caso que nos ocupa se refiere a las gestiones y trámites que las empresas deben realizar frente a la administración pública, éstos deben ser prestados de un modo trasparente y ético, por parte de los distintos servidores públicos que laboran dentro de la misma administración pública. También las personas que solicitan dichos trámites y gestiones deberán solicitarlos conforme a los distintos requerimientos que establezcan las leyes, los reglamentos, acuerdos y circulares administrativas respectivas. Y que muchas veces incluyen formatos o esqueletos que debe llenar el gestor independiente o dependiente de la empresa en que labora.

La corrupción en las empresas es pan nuestro de cada día, ésta se entiende: "Cuando se refiere a las organizaciones, especialmente las públicas, se entiende como una "práctica consistente en la utilización de las funciones y medios de aquellas en provecho económico, o de otra índole, de sus gestores.” (...) El verbo corromper , por su parte, significa " alterar y trastocar la forma de algo", " echar a perder, depravar, dañar, pudrir", “ sobornar a alguien con dádivas, o de otra manera”, o "prevenir, o seducir a alguien”. (...) se trata de alterar la esencia de un proceso mediante, componendas que generan ventajas indebidas." (Ochoa: 
206) La corrupción representa un problema grave tanto en las empresas privadas como en las dependencias o instituciones del Estado, que traen como consecuencia la desconfianza de la sociedad, erradicarla es muy complejo, pero disminuirla, parece ser más fácil, en la medida que se ataque desde su origen se combatirá de manera eficaz.

Muchos trámites y gestiones se realizan ante las dependencias de gobierno, son largos y complejos, lo que fomenta la corrupción, en la medida de que los trámites se realicen través de medios tecnológicos, considero que de alguna manera la corrupción disminuirá, aunque la vulnerabilidad de la tecnología es muy frecuente, por lo hay que tomarla en cuenta y aplicar dispositivos de control. Sin lugar a dudas la tecnología ha ocupado una parte importante en los procesos, tanto internos como externos de la empresa, por lo que estos procesos deben estar auditados y tener candados que permitan la transparencia en dichos trámites o gestiones, además considero que no deben ser onerosos para los solicitantes, ya que fomenta la corrupción.

En épocas anteriores, por falta de tecnología, se realizaban un mayor número de trámites en las ventanillas de las oficinas públicas o gubernamentales, lo que traía algunas conductas de corrupción, alteración de documentos, dádivas, entro otras corruptelas, por existir un mayor contacto entre la autoridad y el particular, a pesar de que en principio no debiera corromperse el proceso, pero por desgracia no es así, pues es ser humano es impredecible.

Es un problema complejo la cantidad de trámites que se llevan a cabo frente a las distintas dependencias, considero que en la medida que se disminuyan dichos trámites y se eduque tanto a los servidores públicos como a la ciudadanía disminuirá la corrupción en dichos procesos. Incluso nuestro presidente electo intenta disminuir ciertas obligaciones de las empresas en las que ante todo se parta de la confianza del ciudadano y en su caso del contribuyente, con lo que se pretende disminuir la tramitología y buscar la simplificación administrativa, espero que no quede en buenos deseos y que tanto la sociedad como la administración pública actúen con principios de honradez y éticos, pues como ya lo he mencionado, lo que hace falta es educar a las personas, darles sueldos dignos a los servidores públicos y en general crear un ambiente transparente de certidumbre en todos los procesos que se realicen frente a las distintas dependencias y autoridades gubernamentales.

El exceso de trámites y procedimientos engorrosos y la desconfianza extrema al público, sean contribuyentes o ciudadanos, generan mayor corrupción, disminución en la captación de recursos para el Estado, ahuyenta inversionistas extranjeras y nacionales, retrasa los trámites administrativos, complica los procesos, entre otras consecuencias nocivas para el 
público en general y para la administración pública; es un signo negativo para todos los países en vías de desarrollo como es el nuestro.

En el orden internacional existen mecanismo para el combata a la corrupción: "La Convención Interamericana contra la corrupción (CICC) y la Convención de Naciones Unidas contra la corrupción. (CNUCC) Ambos documentos suscritos y ratificados por México. El primero entre otras cosas, tiene por objeto, prevenir y sancionar la corrupción cooperando los Estados parte. Prohíbe y castiga el soborno trasnacional y el enriquecimiento ilícito de funcionarios públicos. En el segundo busca la cooperación internacional con apoyos técnicos para combatir la corrupción. Se obliga a los Estados a tipificar como delito el soborno de los funcionarios públicos, nacionales, extranjeros y de organizaciones internacionales públicas, así como el peculado y el tráfico de influencia, el abuso de funciones y el enriquecimiento ilícito. “(Ibid: 207) Como se desprende de lo anterior, la corrupción es un problema mundial, sin embargo los controles y la lucha contra dicho cáncer, depende de cada país y también influyen los organismos internacionales con los que sean parte y que los obliguen a combatirla de manera eficaz.

\section{- Las empresas y sus trámites y servicios frente a la administración pública.}

La empresa tiene íntima relación con los diversos entes de la administración pública, existen un sinnúmero de trámites y gestiones que están obligados a realizar las empresas con las distintas dependencias de la administración pública, que se encuentran contenidas en diferentes leyes y reglamentos de dichas dependencias, gestiones que son necesarias para el desarrollo de sus actividades.

La empresa como la actividad que realizan las sociedades, se ven en la necesidad de contar con un departamento de gestoría o contratar gestores externos, para que lleven a cabo los trámites administrativos que requiere la empresa, desde una licencia de uso de suelo, hasta el alta de los trabajadores en el Seguro Social, gestiones que implican erogaciones para los empresarios y que muchas veces son engorrosas para las personas que los tramitan, debido a la burocracia administrativa, al exceso de requisitos que se necesitan para dichos trámites, entre otras causas.

Sin duda México es uno de los países en el que los trámites son largos y tediosos, muchas veces lo que ha generado la corrupción que existe, por lo que es conveniente educar a la gente, empleados o servidores públicos de las dependencias de la administración pública, a gestores y en general a todos aquellos que se ven involucrados en dichas gestiones o procesos. 
Por lo que es importante, que las empresas apliquen en sus trabajadores códigos de conducta moral, lo que permite un desarrollo sano dentro y fuera de la corporación. "La relevancia de la ética en la empresa se debe tanto a su impacto directo en la sociedad como al carácter constitutivo de las sociedades modernas." (Domínguez, 2012: 20) El tener valores por parte de los dueños, trabajadores y en general cualquier persona que forme parte de la empresa es indispensable, ya que eso mejora su calidad en la producción, el servicio con sus clientes, las relaciones con los proveedores y en todos los ámbitos de la empresa.

Pagar sueldos dignos a los trabajadores contribuye a un saneamiento de la empresa, sea institución pública o empresas privada, ya que con ello se disminuye la corrupción, además "en lo referente a salarios e ingresos, la administración de trabajo deberían enfocar su actividad a permitir el aumento del ingreso real de los trabajadores, así como a evaluar y difundir objetivos e informaciones confiables acerca de cuestiones tales como: nivel general de salarios, análisis de salarios, modelo de consumo, canasta familiar, etc." (Naime, 1993: 20) Si se pagan los salarios reales se mejoraría la calidad de vida de los trabajadores mexicanos y de sus familias, el gasto en su canasta básica sería conforme a sus necesidades. “en este contexto la administración pública del trabajo se ha constituido en uno de los instrumentos fundamentales de la política del estado para cumplir con el propósito equilibrador y estabilizador del sistema, por el cual, la política laboral de un estado se hace efectiva comprendiendo no solo aspectos de conciliación o administración de justicia, sino que también incide de manera directa en factores de la producción (tales como el capital y trabajo, empleados y prestadores de servicios) orientando sus acciones y estableciendo derechos y obligaciones." (Ibid: 18) Por lo que los factores de la producción deben estar armónicos y libres de cualquier injerencia que opaque su función, como es el caso de la corrupción que tanto daña a la sociedad mexicana. Es importante implementar acciones que combatan conductas negativas en los factores de la producción y ofrecimiento de los servicios.

El Estado debe estar al pendiente del correcto funcionamiento de la administración pública, así como de las distintas corporaciones públicas o privadas. "el papel del Estado se ha manifestado por su intervención como legislador, como promotor de la política laboral y como empleador, todo ello dentro del marco de una política laboral que no puede ser definida e instrumentada si se desconocen los actores sociales que en ella participan." (Ibid: 21) Como ya lo hemos mencionado, dichos actores sociales, pueden ser empresarios, organizaciones no gubernamentales, los grupos consumidores, por mencionar algunos, mismos que son indispensables para los procesos de producción y que deben estar libres de cualquier vicio o 
defecto que vaya en contra de los principios éticos, de los que podemos destacar tanto de parte de los empresarios y sus trabajadores como de las distintas entidades públicas, constituidas por los diferentes servidores públicos, que tengan injerencia en el proceso productivo y en los servicios que llegan al consumidor final.

Existen distintas opiniones, respecto a las maneras de disminuir la corrupción en los trámites y gestiones administrativas, una de ellas se refiere a lo siguiente: "La eliminación del soborno, sea como mecanismos de aseguramiento o para la obtención formal del trámite, requiere una estrategia que modifique los incentivos no solo del ciudadano, sino también del funcionario, con la condición de que el soborno debe ser inferior al costo evitable pero superior al valor esperad del riesgo del funcionario. La coalición corrupta, a través de los contratos de corrupción puede dispersar el riesgo e incrementar artificialmente el costo evitable, con lo cual podrán modificar los incentivos del ciudadano para orientar su acción a la solución con soborno." (Vértiz, 2000:344) Como podemos apreciar el aspecto económico es un factor importante en el fomento a la corrupción. Sin embargo, como ya lo he dicho en el desarrollo del presente artículo, considero que la cuestión de la educación en los servidores públicos, que realmente sean profesionales de carrera y la concientización en los ciudadanos, puede ser un factor importante para la disminución de las conductas corruptas y los contratos a que se refiere el autor, pero que son verdaderos acuerdos establecidos entre el corruptor y el corrupto, que actúan fuera de la ley y por supuesto de principios éticos y morales.

\section{De acuerdo a lo anterior, se concluye:}

- La empresa es fundamental en la producción y distribución de bienes y servicios que van destinados al consumidor final, tanto en el ámbito nacional como en el internacional, por lo que sus procesos deben ser éticos, morales, sin corrupción, transparentes y tendientes a un bienestar de la colectividad.

- El Estado debe garantizar la protección de las empresas, tanto públicas como privadas y que no vayan en contra de las leyes, reglamentos, acuerdos y circulares administrativas en función del bienestar de las mismas e indirectamente del público consumidor.

- La corrupción en los trámites y gestiones que realizan las empresas frente a la administración pública es un cáncer que debe combatirse, genera destrucción en la sociedad y va en contra del bienestar económico, social, político, ambiental, etc. 
- México es uno de los países en el que los trámites son largos y tediosos, muchas veces generado por la corrupción, por lo que es conveniente educar a la gente, empleados de las dependencias de la administración pública, a gestores y en general a todos aquellos que se ven involucrados en dichas gestiones o procesos.

- El empresario es un líder, que debe llevar a la empresa a los mejores resultados, buscando innovaciones o creaciones con su respectiva originalidad, que compitan en el mercado de los consumidores de modo sano.

- Para el logro y cumplimiento de los planes y objetivos de las empresas, se implementan distintos trámites y gestiones dentro de la administración pública en el que hacer, para el desarrollo de la agenda pública, lo que implica el contacto constante entre el sector público y privado.

- El exceso de trámites y procedimientos engorrosos y la desconfianza extrema al público, sean contribuyentes o ciudadanos, generan mayor corrupción, disminución en la captación de recursos para el Estado, ahuyenta inversionistas extranjeras y nacionales, retrasa los trámites administrativos.

- El uso de la tecnología en los trámites y gestiones puede ser una manera de disminuir la corrupción, sin embargo hay que considerar la vulnerabilidad de ésta, por lo que se deben implementar, auditorías y controles en los dispositivos tecnológicos.

- La educación en los servidores públicos, que realmente sean profesionales de carrera y la concientización en los ciudadanos, puede ser un factor importante para la disminución de las conductas corruptas o acuerdos establecidos entre el corruptor y el corrupto que se encuentran fuera de la ley.

- Los trámites y las gestiones representan un gran impacto en dichos procesos productivos, mismos que no se deben escatimar ni demeritar o corromper al momento de requerirlos, en la medida que sean respetados y cumplidos cabalmente, se tendrán resultados positivos tanto para la empresa, la administración gubernamental y el público consumidor final. 
- En la medida de que se cumplan como lo disponen las distintas leyes, reglamentos, acuerdos o circulares administrativas en la realización de los trámites y gestiones frente a la administración pública, considero que se estará actuando de manera ética y con responsabilidad social.

The company and the public administration: procedures and management.

\begin{abstract}
The company in its development has many rights and obligations, which is why it is necessary to carry out different procedures and managements before the public administration, which are contained in the different laws and regulations. We must consider that there is a cancer called corruption, which delays such efforts, or taints, so that both public servants dependent on different entities of the public administration as the people or managers who have to perform the procedures, must be clean of corruption and act in accordance with ethical principles that contain solid values tending to the welfare, both of the company and of the public administration in pursuit of the common good of society, to whom it is directed of the different groups of final consumers.
\end{abstract}

Keywords: Company, public administration, procedures, ethics, corruption.

\title{
Bibliografía.
}

Víctor Rafael Aguilar Molina. Empresa. Revista Mexicana de Derecho. Número 9. Colegio de Notarios del Distrito Federal. México. 2007. Consultado en el 2018, en : http://historico.juridicas.unam.mx/publica/librev/rev/mexder/cont/9/cnt/cnt8.pdf

Guillermo Domínguez Chávez. (2012) "Responsabilidad social empresarial.” Editorial Pearson.

Jorge Fernández Ruíz (S.A) Derecho Administrativo Colección INEHRM p.90 consultado en el 2018 en: https://archivos.juridicas.unam.mx/www/bjv/libros/9/4455/8.pdf

Alexander Naime Libien. (1993) "La evolución de la administración pública del trabajo en el estado de México.” Editorial UAEM, IAPEM, Imagen editores.

Roberto A Ochoa Romero.(S.A.) Corrupción significado y estrategias internacionales y nacionales para su prevención y persecución.. Consultado en 2018 en: https://archivos.juridicas.unam.mx/www/bjv/libros/9/4315/24.pdf 
Miguel Ángel Vértiz Galván. (2000) El combate a la corrupción en los trámites administrativos. Una aproximación teórica. Gestión y política pública Vol IX Número 2. México. Consultado en el 2018 en: http://www.redalyc.org/articulo.oa?id=13309204

\section{Legislación.}

Código Fiscal de la Federación.

Ley Federal del Trabajo.

Trabalho recebido em 18 de janeiro de 2019

Aceito em 26 de janeiro de 2019 